\title{
The Construction of Indicator System for Performance Measurement of Chinese Enterprises Based on Balanced Scorecard
}

\author{
Yong Cheng ${ }^{1}$ \\ ${ }^{1}$ School of Business Administration, Shenyang University, Shenyang, China \\ Correspondence: Yong Cheng, No. 54, Lianhe Road, Dadong District, Shenyang 110041, China. E-mail: \\ 19781978cy@163.com
}

Received: March 15, 2012 Accepted: April 20, $2012 \quad$ Published: July 1, 2012

doi:10.5539/ass.v8n8p155

URL: http://dx.doi.org/10.5539/ass.v8n8p155

\begin{abstract}
With the in-depth development of China's market economy, the number of listed companies is growing. Enterprises face more complicated internal and external environment. It is an urgent to improve and construct a set of effective indicator system for performance measurement of Chinese enterprises, guaranteeing the healthy development of Chinese enterprises and maintaining the legal rights and interests of investors. In perspective of balanced scorecard, starting from the definition of enterprise performance measurement, this paper analyzes the problems and causes of performance measurement indicator system of Chinese enterprise, and proposes strategies for its improvement.
\end{abstract}

Keywords: balanced scorecard, performance measurement, indicator system, construction

Enterprise performance measurement is to make a comprehensive assessment of enterprise's overall business performance and operation efficiency. For enterprise performance measurement, the measurement subject uses mathematical statistics and operations research, adopts special indicator system, references to unified measurement standards, follows certain procedures, makes quantitative and comparative analysis, and achieve the objective, fair, and accurate comprehensive measurement of business performance and operation efficiency in certain period. The indicator system for enterprise performance measurement is the collection of indicators for the comprehensive measurement of enterprise's overall business performance and operation efficiency. By means of building the indicator system for enterprise performance measurement, investors can predict the future business performance of different enterprises, for the sake of acquiring the maximum benefits; creditors can determine the borrowing of their funds, ensuring the safety of principals and the maximum interests; enterprise managers can know their competitors' and their own business performances and changes, what would be helpful for the formulation of competition strategy.

\section{The Definition of Indicator System for Performance Measurement of Chinese Enterprises}

From the 1990s to the present, the "Strategic Balanced Scorecard" proposed by Professor Robert S. Kaplan in Harvard University and president of American Recovery Corporation David P. Norton, and the Rules for Measuring the Effective Performance of State-owned Capital circulated and implemented by four ministries in June 1999 in China have make useful trying in the construction of indicator system for enterprise performance measurement.

The core of "balanced scorecard" is the management philosophy of "get whatever you measure". As the enterprise chooses the performance measurement indicators, it should take into account the balance between the long-term and the short-term, the financial and the non-financial, the internal and the external, the advanced (driving) and the lagged (result), which is the meaning of balance in "balanced scorecard". The "balanced scorecard" puts some seemingly loose competitive factors in one management report, helping senior managers to focus on few key indicators, emphasize on enterprise's long-term management issues, consider all important operation indicators, and prevent the situation of catch-one-and-lose-another. The approach of "strategic balanced scorecard" proposes a set of indicator system for the measurement of enterprise performance, i.e. the strategic balanced scorecard indicator system, including four aspects, namely the finance, the customer satisfaction, the internal business process, and leaning and innovation. The relations of the four aspects are: the financial performance measurement indicator system is fundamental, and all other indicator systems serve it. The 
financial performance measurement indicator system reflects enterprise's solvency (such as asset-liability ratio), operation capabilities (such as accounts receivable turnover, and inventory turnover rate), profitability (such as return on net assets, return on investment, margins, and operating profit margin), and other basic qualities. Each measurement indicator has a cause-effect relation with balanced scorecard in some way. The performance measurement indicator system can reflect the basic motives for performance. The four aspects can be adjusted by enterprise according to specific situations and passage of time.

The existing enterprise performance measurement indicator system in China was jointly published by the Ministry of Finance, the State Economic and Trade Commission, the Ministry of Personnel, and the State Planning Commission in June 1999, including eight basic indicators, sixteen correct indicators, and eight appraisal indicators. The contents of Chinese enterprise performance measurement indicator system cover four fields: asset income, asset operation, solvency, and development capacities. In perspective of the depth of study, it has three layers: basic indicators, correct indicators, and appraisal indicators. In the overall layout, it focuses on quantitative financial indicators, assisted by qualitative non-financial indicators, to form the final conclusion on enterprise performance measurement. At present, the indicator system has basically satisfied the needs for industrial and commercial competitive enterprise management measurement, since it can reflect the overall business performance objectively. From common Chinese industrial and commercial enterprise performance measurement indicator system, the financial indicator system for enterprise performance measurement is divided into three layers: basic indicators, correct indicators, and appraisal indicators. The specific contents include: financial conditions, including two basic indicators of rate of return on common shareholders' equity, and return on total assets, and three correct indicators of capital maintenance and increment ratio, sales (operating) profit margins, and cost margins; assets operating conditions, including two basic indicators of total asset turnover and liquidity asset turnover, and four correct indicators of inventory turnover rates, accounts receivable turnover ratio, rate of non-performing assets, and asset loss ratio; solvency conditions, including two basic indicators of asset liability ratio and multiples of earned interests, and five correct indicators of liquidity ratio, quick ratio, ratio of cash to current liabilities, favorable ratio of long life properties, and credit business loss ratio; development capabilities, including two basic indicators of sales (business) growth rate and rate of capital accumulation, and four correct indicators of total asset growth rate, wear rate of fixed assets, 3-year average growth rate of profits, and 3-year average capital growth rate. In addition, the appraisal includes indicators of basic quality of leading bodies, ability of occupying product market (service satisfaction), level of basic management, quality of current staff, update of technologies and equipments (hard service environment), industrial or regional influences, industrial development strategy, and long-term development prediction. By analyzing basic indicators, people can know about the general conditions of enterprise business management; by examining the correct indicators, people can further adjust and improve the measurement results based on basic indicators from multiple aspects. As for appraisal indicators, people can assess enterprise's business performance from the perspective of qualitative analysis.

\section{Problems and Causes Analysis in the Construction of Indicator System for Performance Measurement of Chinese Enterprise}

Although the existing performance measurement indicator system has its advantages and effects, the traditional measurement method based on financial statements cannot solve its birth defects, i.e. the inner defect which takes the measurement indicator system as the main basis for analysis and measurement, caused by the method itself, even after its improvement and maturity.

\subsection{The Arrangement of Performance Measurement Indicators Is Not Perfect or Completely Rational}

It emphasizes on financial indicators for measurement. The existing enterprise performance measurement indicator system has eight basic indicators and sixteen correct indicators, what are all financial indicators. There are only eight non-financial indicators. Financial indicators are easily affected by policy choice, making measurement fail to achieve a true reflection of the objective reality. The mode of taking accounting standards as accounting policies provides alternatives for accounting treatment of certain economic matters, saving more spaces for enterprise choosing accounting policies. Too much emphasis on financial measurement may force enterprise to pursue for high financial indicators, neglecting long-term interests, and causing short-term behaviors. Accordingly, although financial indicators are the main body of measurement indicators, excessive use of these indicators will result in many drawbacks.

The non-financial indicators are not perfect. The non-financial indicators of existing enterprise performance measurement indicator system are subjective. Eight non-financial indicators are non-quantifiable, including the basic quality of enterprise leadership team, product market occupation, service satisfaction, level of basic 
management, staff quality, update of technologies and equipments, hard environment for services, industrial or regional influences, enterprise business development strategy, and prediction for long-term development capability. Qualitative analysis depends on people's understandings and experiences of economic phenomena. Therefore, the non-financial indicators acquired merely by qualitative analysis are more subjective and arbitrary and cannot guarantee the objectivity of measurement results. The existing non-financial indicators are incomplete, due to the lack of measurement indicators about enterprise's credibility, intelligent and knowledge capitals.

The use of cash flow indicator analysis is rare and the cash flow-related financial indicator is only the ratio of cash to current liabilities. The financial indicators of the balance sheet and profit statement on the accrual basis cannot fully reflect the real and changeable economic facts. The cash flow analysis on the cash basis can make necessary supplement for the measurement of enterprise's operating capacity, quality of earnings, and debt risk, improving the financial analysis and measurement of enterprise. The enterprise with profits and high current ratio not necessarily possesses sufficient cashes for sustainable development and solvency. It is necessary to make cash flow analysis.

\subsection{The Design of Calculation of Mean Weight Is Not Reasonable}

The weight should be designed to take full account of the specific requirements of subjects of enterprise performance measurement. According to accountability theory, subjects of performance measurement should include state management agencies, assets owners, major shareholders, and the enterprise itself. For different shareholders, the relative importance of each indicator is inconsistent. For example, for enterprise owners, they pay more attention to maintenance and increment of capital values, giving the priority to the safety of principals. For enterprise creditors, such as banks and corporate bond holders, they pay more attention to the solvency of enterprise, taking indicators that reflect the solvency of enterprise as the most important indicators. For the enterprise itself, it is more concerned about the current profits and development capability. Thus, the fixed weight values cannot meet the actual needs of all shareholders. In addition, to design the fixed weights should take the industrial differences of enterprises into consideration. Different industries, such as the manufacturing industry and the catering industry, the construction enterprise and the securities industry, have different levels of profitability, asset-liability ratios, and liquidity ratios. Therefore, using the fixed weight values, regardless of industries, cannot meet the actual needs of performance measurement.

\subsection{The Mean Calculated by the Method Is Poor for Presentation}

To calculate the mean is to reflect the different levels of representation. However, the mean calculated by the method is poor for presentation. According to Indicator Explanations for Rules for Measuring the Effective Performance of State-owned Capital, indicators using the mean as the numerator or denominator include the return ratio on net assets, the total asset turnover, the current asset turnover, the inventory turnover, receivables turnover, and the wear rate of fixed assets. Here, the mean = (the number at the very beginning of one year + the number at the end of the year)/2. This formula only considers conditions at the beginning of the year and at the end of the year, without including conditions during the year. As a matter of fact, for many enterprises, the assets conditions vary in every month and even differ significantly, and the changes are uneven. Therefore, the mean calculated by this way is poor for representation and cannot reflect the actual conditions of the enterprise objectively or precisely. Thus, the financial indicators calculated by this method cannot achieve the objective and fair performance measurement.

\section{Thoughts on Building and Improving the Indicator System for Performance Measurement of Chinese Enterprises and Countermeasures}

The sustainable development of a country's economy depends on the steady and healthy development of securities market and listed companies, and the appropriate measurement of enterprises. Based on the balanced scorecard theory and regulations in Rules for Measuring the Effective Performance of State-owned Capital, we need more adjustment and improvement in building and improving the indicators system for performance measurement of Chinese enterprises.

\subsection{Design the Performance Measurement Indicators Precisely}

Take the input-output analysis as the starting point. In order to survive, the enterprise must achieve the goal of more income than costs. Under the circumstance of market economy, the business activities are the capital operating process by the enterprise. Business objective is to achieve capital maintenance and increment of values. The relationship of returns and costs becomes the one between capital realization and advanced capital. The pursuit of maximum increment of capital values is the purpose for production. Focus on the combination of 
quantitative analysis and qualitative analysis in input-output analysis in order to compensate the shortcomings of qualitative analysis. In performance measurement, it is difficult to make a comprehensive measurement of business performance only by quantitative analysis because many business operations cannot be reflected by numbers, but must by some qualitative indicators, such as environment protection, intelligence of employees, and management levels, to achieve an overall measurement of enterprise's strategic business performances.

Emphasize on the coordination of new measurement indicators and important indicators. Increase the cash flow-related measurement indicators appropriately. Considering the importance of cash flow to enterprise performance, it is necessary to develop new cash flow indicators in operational capabilities, quality of returns, and solvency, in order to compensate the defects. The reasonable choices should include cash ratio of sales, cash flow per share operational activity, cash ratio of main business income, and cash ratio of matured liability.

Increase non-financial indicators and make them be quantitative as much as possible. First, design new non-financial indicators to improve the accuracy of financial indicators. Financial indicators reflect business results, while non-financial indicators reflect business process. There is certain relationship between results of financial indicators and that of non-financial indicators. In addition, results of non-financial indicators come from many aspects, but not depend on financial department, e.g. data of market share can be obtained from social survey agencies. Therefore, the existence of non-financial indicators reduces risks of financial indicators playing number games, thereby increasing the accuracy of financial indicators. Second, design the non-financial indicators reflecting enterprise credibility. The enterprise credibility mainly concerns the timely repayment of debts, payment, delivery, quality and commitment. Therefore, the credibility affects business operations to certain degree. It deserves to be an important part in enterprise performance measurement. Especially as current social credit is in chaos, it turns to be more important to measure enterprise performance by credibility. We can use some comprehensive indicators, such as overdue payment ratio, timely delivery ratio, delay payment ratio, and return rates, to make enterprise credibility be quantitative. Third, design new non-financial indicators about customers. Enterprise should possess a customer perspective, which can help managers connect specific customers with market-based strategy in order to create more financial benefits in future. We can use the market share, customer retention rate, customer growth rate, and customer satisfaction to measure the relationship between enterprise and customers. Finally, make non-financial indicators be quantitative as much as possible. Indicators must be quantitative in order to guarantee the objectivity of measurement standards, process, and results. Based on qualitative analysis, we should make quantitative analysis as much as possible. By using quantitative analysis, non-financial indicators will get explicit numerical results. For example, to measure the work conditions of employees, we can make analysis by indicators of staff turnover, rate of staff training, and staff productivity.

The combined use of financial indicators and non-financial indicators reflects the consistency of business objectives and means. Excellent financial success is the most important objective of enterprise. There are four main ways to achieve financial success: give up investment opportunities; reduce costs; reduce expenses; increase prices of products or reduce levels of services; improve technologies of employees, internal management, and customer satisfaction. The first three means only allow the enterprise to obtain short-term financial success, and the fourth can achieve the long-term financial success in future. The main purpose of using non-financial indicators is to drive the enterprise to pursue financial success by the fourth way.

\subsection{Build a Multi-weight Measurement System}

A complete enterprise performance measurement system is multi-level and diversified. We should build a multi-weight measurement system based on different subjects. Since different shareholders view the financial conditions of enterprise differently, it is not appropriate to adopt a fixed weight for enterprise performance measurement. As we build systems with different weights, the first is to know the differences of needs of subjects, e.g. Government management agencies, creditors, investors, and enterprise. The second is to consider the differences of industries, e.g. circulation enterprises, construction enterprises, and IT industries. As for the multi-weight system, we should establish the objects and conditions for each specific weight system. When results are circulated, the whole weight system should be released at the same time.

\subsection{Use the More Accurate Method to Calculate the Mean}

From a statistical point of view, in order to calculate the annual means of net assets, total values of assets, current assets, inventories, accounts receivable, fixed assets, and net fixed assets respectively, a more accurate method is:

Mean $=1 / 2$ number at the very beginning + number at the end of Jan. $+\ldots \ldots+$ number at the end of Nov. $+1 / 2$ number at the end of the year 
To calculate the mean by this method can make the enterprise performance measurement system more objective and reasonable.

In addition, in measuring enterprise performance, we can make multi-factor analysis based on the multi-objective planning theory. Turn the strategic objectives of enterprise into tactical objectives of different stages, and separate strategic objectives into stage-based specific and operable indicator system. By this way, managers and workers at each level can better understand enterprise objectives and strategies, which will benefit the implementation of them in enterprise. Besides, performance measurement should combine with financial analysis, examining problems by DuPont Financial Analysis and multi-factor analysis.

Meanwhile, compare enterprise's business results by relatively objective standards. Measurement indicators are the scale for the value judgment of business performance. The value judgment is based on measurement standard system. Different standards lead to different measurements. If an enterprise's business performance is progressing annually, it will get a positive result of good performance; if compared with other enterprises in the same industry, the enterprise is at the bottom, it will get a negative result of bad performance. Therefore, we must choose the objective measurement standards to make enterprise performance measurement.

\section{References}

Jiao, Ying. (2010). On the enterprise performance measurement system. Charming China, 35, 38.

Ministry of Finance, People's Republic of China. (1999). Rules for Measuring the Effective Performance of State-owned Capital. Indicator Explanations for Rules for Measuring the Effective Performance of State-owned Capital.

Robert S. Kaplan, \& David P. Norton. (2006). Alignment: Using the Balanced Scorecard to Great Corporate Synergies.

Wang, Fangxiao. (2011). An exploration on enterprise performance measurement system. Modern Economic Information, 19, 121.

Zhang, Rui. (2002). The Measurement Indicator System for Enterprise Performance. Beijing: China Financial \& Economic Publishing House. 